\title{
Trend Analysis of Mortality Rates for Leading Causes of Death Among Under-Five Children in Iran, 2000 - 2015
}

\author{
Salman Khazaei ${ }^{1}$, Farid Najafi ${ }^{2}$, Vajihe Armanmehr ${ }^{3}$, Mahmoud Hajipour (iD ${ }^{4}$, Manoochehr Karami ${ }^{5}$ \\ and Shahab Rezaeian ${ }^{6, *}$ \\ ${ }^{1}$ Department of Epidemiology, School of Public Health, Hamadan University of Medical Sciences, Hamadan, Iran \\ ${ }^{2}$ Research Center for Environmental Determinants of Health (RCEDH), Health Institute, Kermanshah University of Medical Sciences, Kermanshah, Iran \\ ${ }^{3}$ Social Determinants of Health Research Center, Gonabad University of Medical Science, Gonabad, Iran \\ ${ }^{4}$ Student Research Committee, Kermanshah University of Medical Sciences, Kermanshah, Iran \\ ${ }^{5}$ Modeling of Noncommunicable Diseases Research Center, Hamadan University of Medical Sciences, Hamadan, Iran \\ ${ }^{6}$ Infectious Diseases Research Center, Kermanshah University of Medical Sciences, Kermanshah, Iran \\ "Corresponding author: Research Center for Environmental Determinants of Health, School of Public Health, Kermanshah University of Medical Sciences, Kermanshah, Iran. \\ Email: shahab.rezayan@gmail.com
}

Received 2018 November 29; Accepted 2019 May 05.

\begin{abstract}
Background: This secondary study is the first to assess the trend of mortality rate and its variations among Iranian children. Methods: The mortality data of under-five children were extracted from the WHO reports. All-cause and cause-specific mortality rates were calculated per 1000 live births and by age groups for each year from 2000 to 2015. The average annual rate of reduction (AARR) was used to determine the changes in mortality rates.

Results: Of 21011 under-five children who died in 2015, 52.3\% were attributed to infectious causes. The overall mortality rate among children under five years decreased from 35 per 1000 live births in 2000 to 16 per 1000 live births in 2015, representing a decline of $55.5 \%$ over the 16-year period with an AARR of 5.5\%. There was a significant decreasing trend in the mortality rates of all causes except for HIV/AIDS and pertussis.

Conclusions: The overall all-cause mortality rate decreased from 2000 to 2015 in Iran although this pattern varied according to the causes of death. There is still a relatively high proportion of mortality rates among children due to congenital anomalies, prematurity, birth asphyxia, sepsis, and acute lower respiratory infections.
\end{abstract}

Keywords: Mortality Rate, Children, Infant, Iran

\section{Background}

Although child mortality has a decreasing trend worldwide (1), it is estimated that more than six million children die before the age of five years (2). This is while most of the death causes are preventable and they predominantly occur in poor countries. There is considerable inequality in the children's mortality rate between countries so that six countries account for $50 \%$ of the under-five deaths worldwide (3). The infant mortality rate (IMR) is one of the most important indices to determine the economic, cultural, social, and public health status of countries (4).

Numerous epidemiological studies have been conducted around the globe on infant and childhood mortality $(2,5-8)$, many of which have reported that more than half of the deaths are attributed to infectious causes (2, $6)$. In addition, based on the global statistics, the leading causes of death include preterm birth complications
(14.1\%), intrapartum-related complications (9.4\%), and sepsis or meningitis (5.2\%), as well as pneumonia (14.1\%), diarrhea (9.9\%), and malaria (7.4\%) among older children (9).

Several studies have used local and national data of infant and children's mortality rates in Iran (10), all of which have focused on the causes of death and reported a decreasing trend in the children's mortality rate based on comparisons with other findings. However, it is not well known whether the fourth Millennium Development Goals (MDGs) regarding a reduction in child mortality by two-thirds between 1990 and 2015 have been achieved (11).

\section{Objectives}

Considering the lack of knowledge regarding the trend of mortality among Iranian children, this study aimed to (i) assess the trend of mortality rate and (ii) quantify the 
magnitude of mortality rate reduction in the Iranian children during 2000 - 2015.

\section{Methods}

This secondary cross-sectional study was conducted in 2016 based on the mortality data of children under five years of age extracted from the World Health Organization (WHO) observatory database (12).

The minimum required data including age groups ( 0 27 days, 1 - 59 months), the cause of death, the year of death, and mortality rate per 1000 live births were extracted from the global health observatory database. The causes of death included congenital anomalies, acute lower respiratory infections, diarrhea, other communicable, perinatal, and nutritional conditions, prematurity, birth asphyxia and birth trauma, sepsis and other infectious conditions of the newborn, tetanus, pertussis, measles, HIV/AIDS, malaria, injuries, and meningitis/encephalitis.

\subsection{Statistics Analysis}

The overall mortality rate was calculated for all causes of deaths by years from 2000 to 2015 and reported by age groups ( 0 - 27 days and 1 - 59 months). Cause-specific mortality rates were also calculated per 1000 live births by age groups and study year.

The average annual rate of reduction (AARR) was calculated using the regression analysis to quantify the changes in mortality rates during the study period. To this end, the mortality rate of each cause was considered as the dependent variable and the year as the independent variable. For example, the mortality rate in our analysis in a baseline year $t_{0}$ (the year 2000) was $Y_{0}$ and 16 data points (2000 2015) after $t_{0}$ were considered for trend analysis; then, each of the 16 points could be written as:

$$
\begin{aligned}
& Y_{t i}=Y_{0} \times(1-b \%)^{\left(t_{i-} t_{o}\right)} \\
& \text { so that } \\
& \begin{aligned}
\ln \left(Y_{t i}\right) & =\ln \left(Y_{0}\right)+\left(t_{i}-t_{o}\right) \times \ln (1-b \%) \\
& =\ln \left(Y_{0}\right)+t_{i} \times \ln (1-b \%)-t_{o} \times \ln (1-b \%) \\
& =\beta \times t_{i}+C_{0}
\end{aligned}
\end{aligned}
$$

where $\beta=\ln (1-b \%)$ is the coefficient of $t_{i}$ and

$$
C_{0}=\ln \left(Y_{0}\right)-t_{0} \times \ln (1-b \%)
$$

is a constant in a simple linear regression of $\ln \left(\mathrm{Y}_{\mathrm{i}}\right)$ against $t_{i}$. Then, using the coefficient $B$, the AARR was calculated based on the following formula (13):

$A A R R=(1-\exp (B)) \times 100$
For example, the AARR of 5.5\% for all causes in Figure 1 was calculated based on Table 1.

$$
\begin{aligned}
A A R R & =(1-\exp (-0.0567)) \times 100 \\
& =(1-0.945) \times 100 \\
& =5.5 \%
\end{aligned}
$$

The $95 \%$ confidence interval $(95 \% \mathrm{CI})$ of mortality rates were assessed by the bootstrap technique with 2000 replications. Statistical analyses were performed using the Microsoft Excel program and the STATA software, version 12 (Stata Corp, College Station, TX, USA).

\section{Results}

More than 52\% of 21011 deaths occurring among under five-year children in 2015 were due to infectious causes. Among 10029 deaths from non-communicable diseases, $47 \%$ and $36.3 \%$ of them were attributed to prematurity and congenital abnormalities, respectively. The mortality rates per 1000 live births by the cause of death and age groups in 2015 are shown in Table 2.

The overall mortality rate of death among children under five years decreased from 35 per 1000 live births in 2000 to 16 per 1000 live births in 2015, representing a decline of $55.5 \%$ over the 16 -year period with an AARR of $5.5 \%$. The rate also decreased by the age subgroups (Figure 1 ).

As shown in Figure 2, there was a significant decreasing trend in the mortality rates among children aged 0 27 days in prematurity $(-54.6 \%, \mathrm{P}=0.009)$, congenital abnormalities $(-38.1 \%, \mathrm{P}=0.064)$, sepsis and other infectious conditions of the newborn $(-52.5 \%, \mathrm{P}=0.051)$, and birth asphyxia and birth trauma $(-50.0 \%, \mathrm{P}=0.021)$.

There is a significant decline in mortality rates of children aged 1 - 59 months related to acute lower respiratory infections $(-60.6 \%, \mathrm{P}=0.002)$, diarrhea $(-77.2 \%, \mathrm{P}=0.001)$, injuries $(-53.1 \%, \mathrm{P}=0.018)$, and meningitis/encephalitis ($65.5 \%, \mathrm{P}=0.006$ ) in $2000-2015$ (Figure 3). During this period, the largest decrease in the mortality rate was observed for diarrhea diseases, from 2.85 per 1000 live births in 2000 to 0.65 per 1000 live births in 2015, representing a decline of $77.2 \%$ with an AARR of $12.8 \%$.

The trend of mortality rates per 1000 live births due to vaccine-preventable diseases among children under five years during 2000 - 2015 is shown in Figure 4. While there was a significant decline in death rates related to tetanus (-81.0\%, $\mathrm{P}<0.001)$ and measles $(-97.5 \%, \mathrm{P}<0.001)$, there was no such a trend in death related to pertussis $(-1.6 \%, \mathrm{P}$ $=0.912$ ).

The trend of HIV/AIDS mortality rate among children under five years increased from 0.0078 per 1000 live births 


\begin{tabular}{lcccc}
\hline Table 1. Results from Regression Analysis for Time Trend of Mortality Rate & & & \\
\hline Mortality Rate & B & Standard Error & P Value & 95\% CI \\
\hline Year & -0.0567 & 0.011 & $<0.001$ & $(-0.0791,-0.0343)$ \\
Constant & 114.91 & 22.89 & $<0.001$ & $(69.97,159.85)$ \\
\hline
\end{tabular}

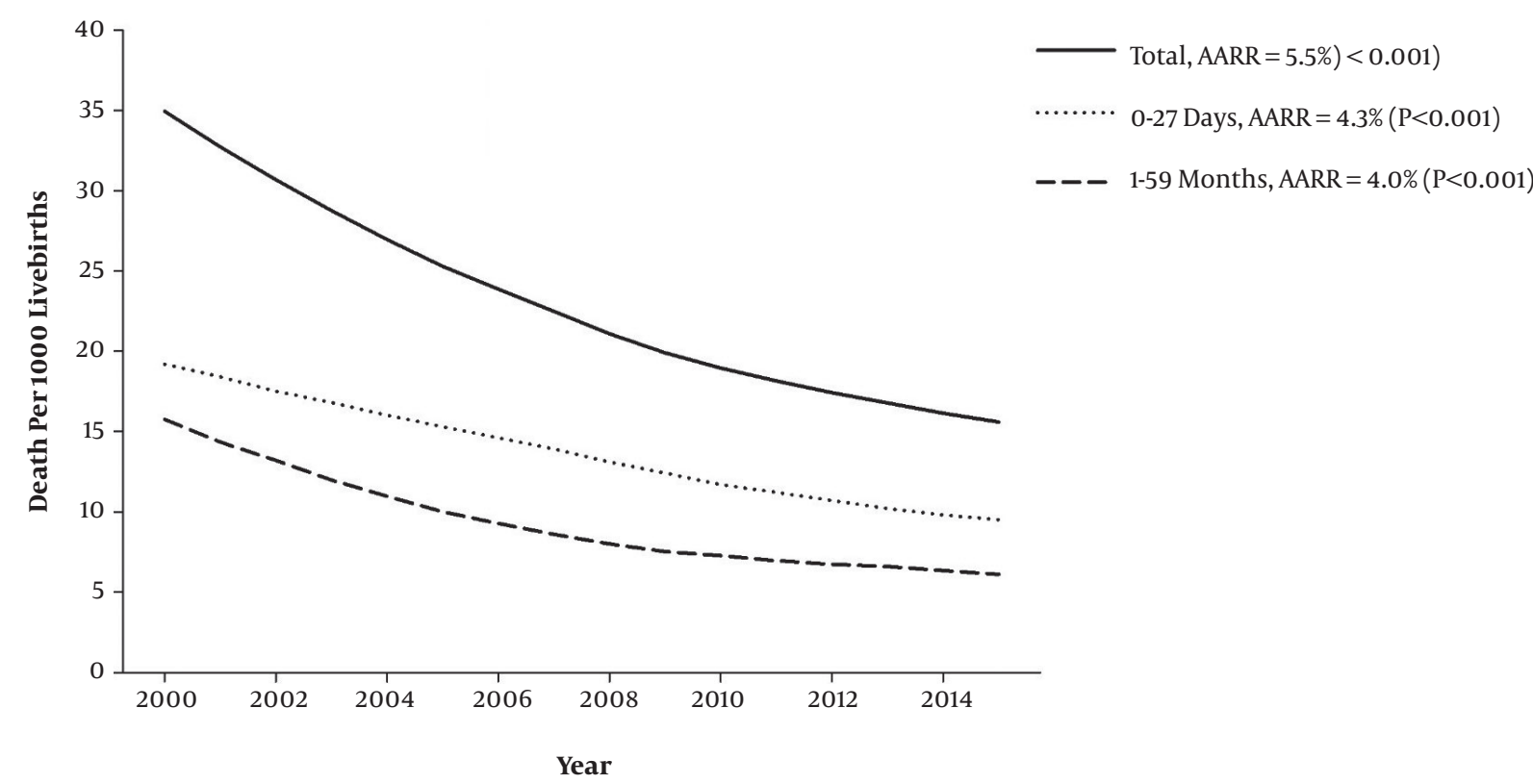

Figure 1. The trend of mortality rates (per 1000 live births) for all causes by age groups, Iran, 2000 - 2015. AARR, average annual rate of reduction.

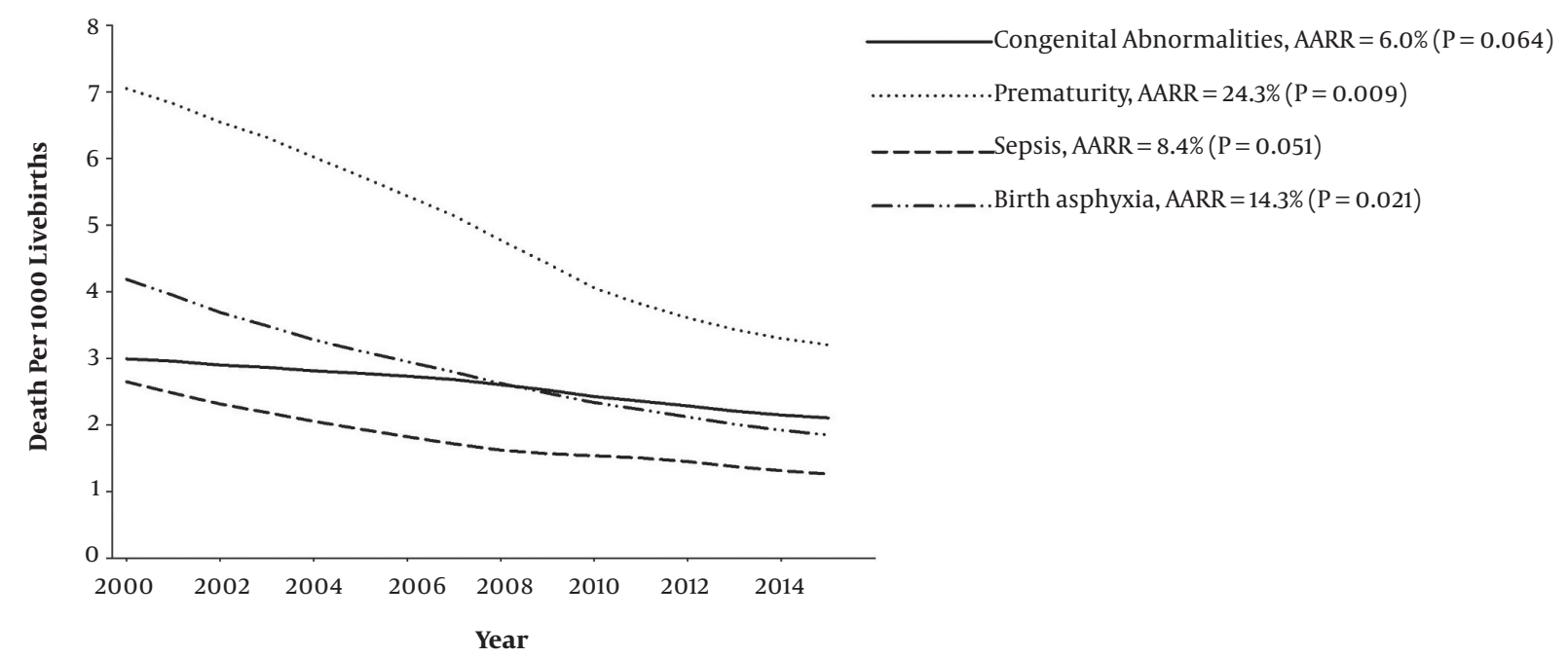

Figure 2. The trend of mortality rates (per 1000 live births) for selected diseases among children aged 0 - 27 days, Iran, 2000 - 2015. AARR, average annual rate of reduction.

in 2000 to 0.021 per 1000 live births in 2015, representing an increase of $169.2 \%$ over the 16 -year period. There was a significant decreasing trend in malaria mortality rate with an AARR of 0.002\% during 2000 - 2015 (Figure 5). 


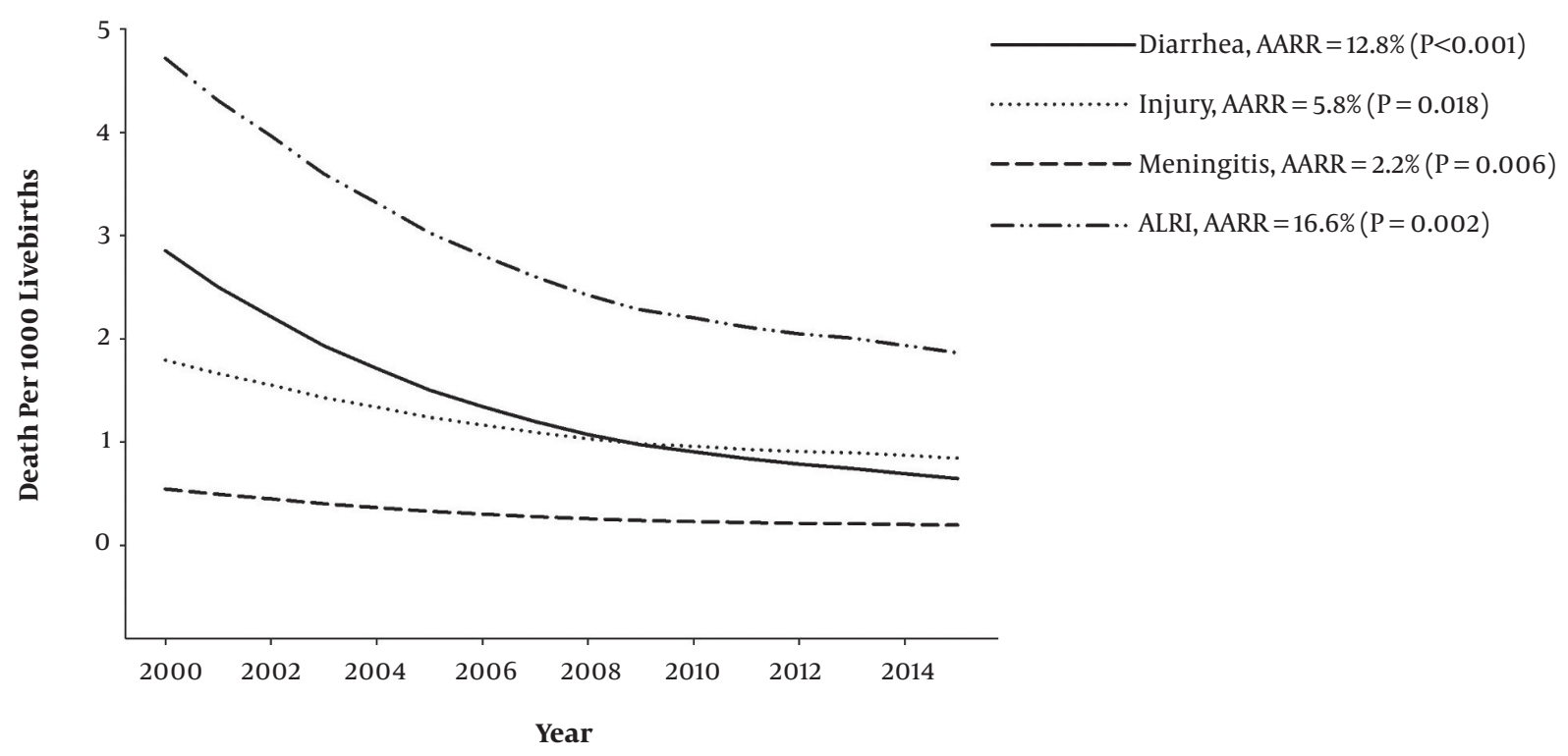

Figure 3. The trend of mortality rates (per 1000 live births) for selected infectious diseases among children aged 1- 59 months, Iran, 2000 - 2015. AARR, average annual rate of reduction; ALRI, acute lower respiratory infections.

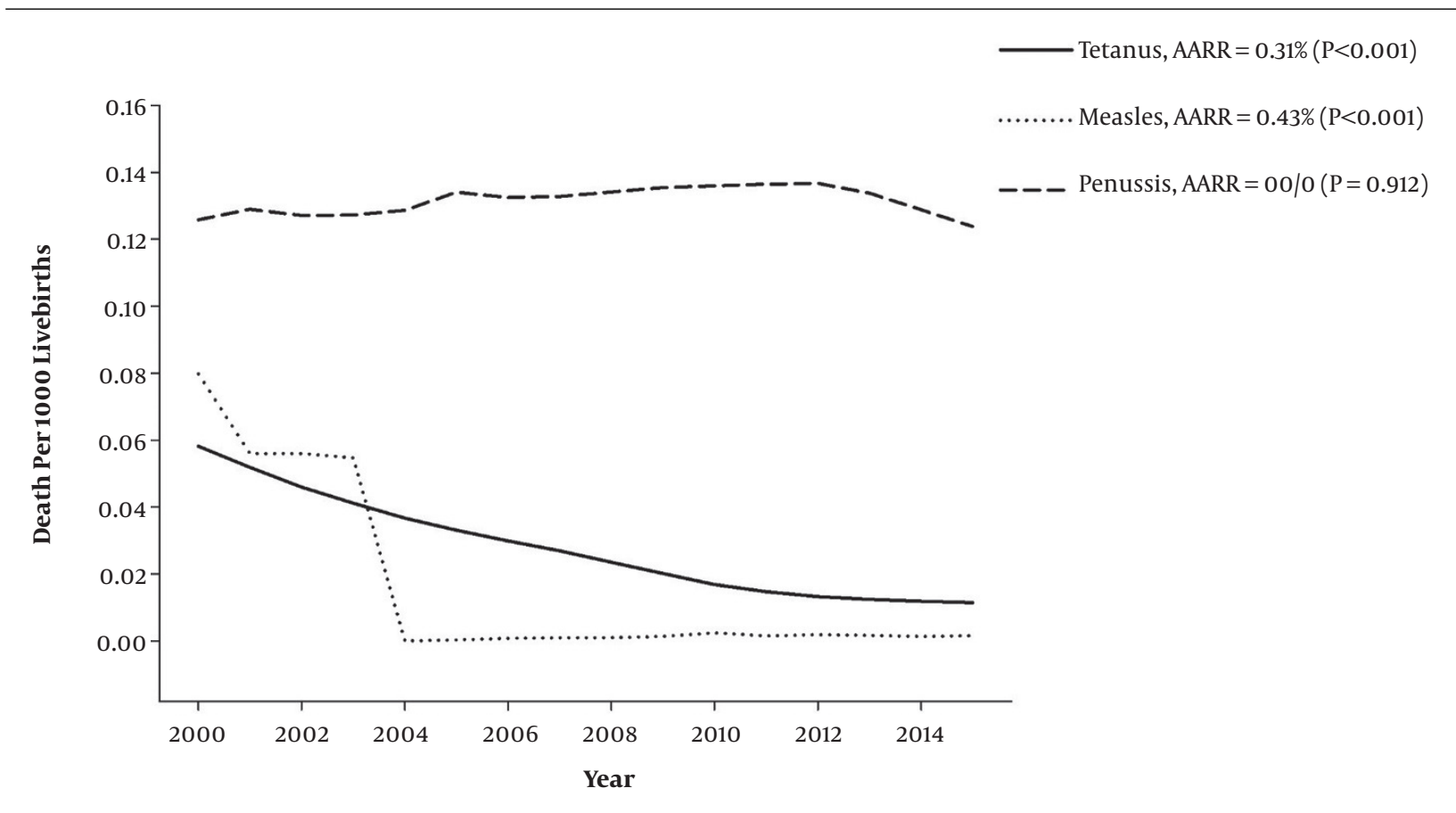

Figure 4. The trend of vaccine-preventable mortality rates (per 1000 live births) among children aged 0 - 5 years, Iran, 2000 - 2015. AARR, average annual rate of reduction.

\section{Discussion}

This study is the first to systematically examine the trend of mortality rates for infectious and non-infectious diseases among Iranian children using official national data. Although several local and national epidemiologic studies have been conducted on children mortality $(7,14$ 16), none of them has examined the trend of mortality rates among children. Therefore, our results fill a gap concern- 

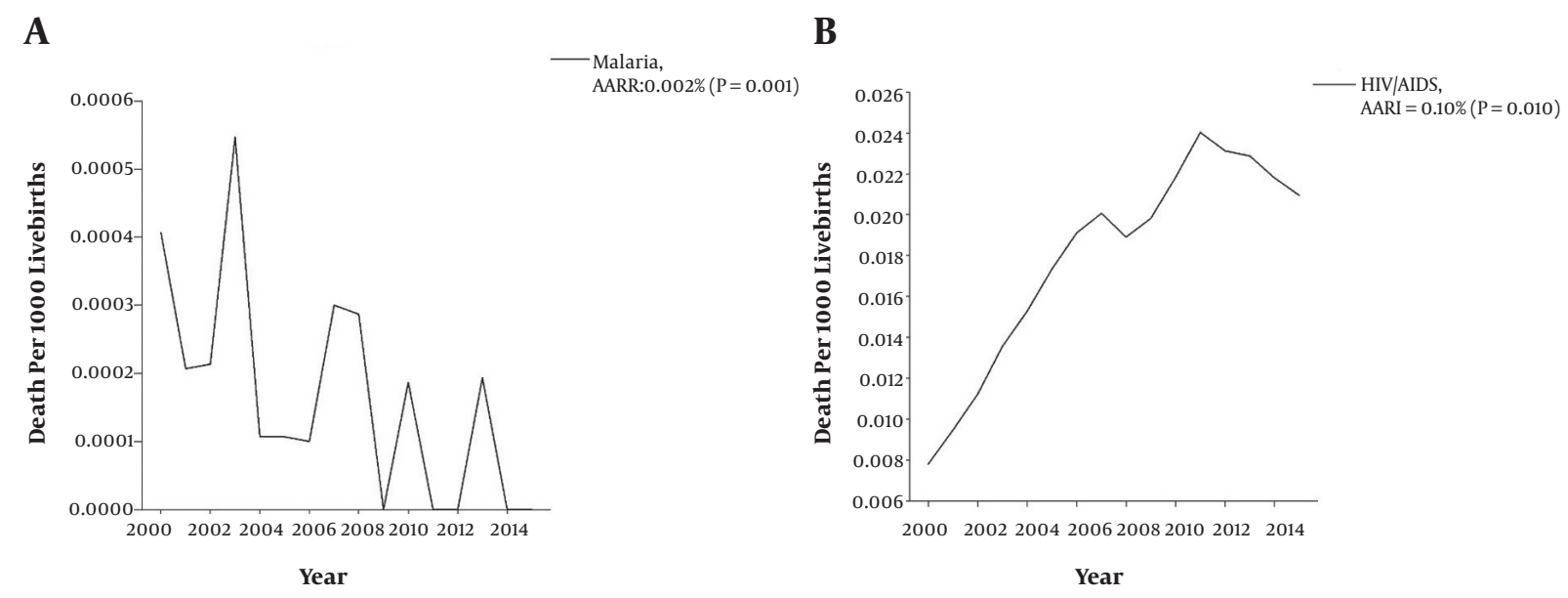

Figure 5. The trend of mortality rates (per 1000 live births) for A, Malaria and B, HIV/AIDS among children aged 0 - 5 years, Iran, 2000 - 2015. AARI, average annual rate of increase; AARR, average annual rate of reduction.

Table 2. Mortality Rates (per 1000 Live Births) and 95\% CI Among Iranian Children by the Cause of Death and Age Groups, 2015

\begin{tabular}{|c|c|c|}
\hline Cause of Death & o - 27 Days & 1 - 59 Months \\
\hline Congenital anomalies & $2.103(0.115-4.092)$ & - \\
\hline $\begin{array}{l}\text { Acute lower respiratory } \\
\text { infections }\end{array}$ & $0.436(0.015-0.858)$ & $1.862(0.042-3.681)$ \\
\hline Diarrhea & $0.016(0.001-0.030)$ & $0.645(0.027-1.264)$ \\
\hline $\begin{array}{l}\text { Other communicable, } \\
\text { perinatal, and } \\
\text { nutritional conditions }\end{array}$ & $0.478(0.014-0.942)$ & $0.332(0.035-0.629)$ \\
\hline Prematurity & $3.199(0.093-6.304)$ & - \\
\hline $\begin{array}{l}\text { Birth asphyxia and } \\
\text { birth trauma }\end{array}$ & $1.847(0.202-3.491)$ & - \\
\hline $\begin{array}{l}\text { Sepsis and other } \\
\text { infectious conditions of } \\
\text { the newborn }\end{array}$ & $1.261(0.088-2.434)$ & - \\
\hline Tetanus $^{b}$ & 0.016 & 0 \\
\hline Pertussis & - & $0.176(0.005-0.348)$ \\
\hline HIV/AIDS & - & $0.031(0.001-0.060)$ \\
\hline Measles & - & $0.002(0.0001-0.0044)$ \\
\hline Injuries & - & $0.843(0.053-1.632)$ \\
\hline Malaria & - & 0 \\
\hline Meningitis/encephalitis & - & $0.194(0.013-0.376)$ \\
\hline
\end{tabular}

ing the lack of information on the trend of mortality rates in a developing country.

We found a significant decreasing trend in the mortality rates of all causes and by age groups. The under-five allcause mortality rate decreased from 35 (95\% CI: 13.6 - 56.3) to 16 (95\% CI: 5.7 - 28.7) per 1000 live births in 2000 - 2015. The AARR of $5.5 \%$ found in this study was higher than the rates of some neighboring countries (17) like Iraq (AARR = $2.1 \%)$, Pakistan $($ AARR $=2.1 \%)$, and Saudi Arabia $(A A R R=4.5 \%)$ and lower than the rate of Turkey (AARR $=6.8 \%$ ). Similar studies from China showed a downward trend in underfive mortality rate by $71 \%$ from 1990 to 2008 , which was mainly attributed to declines in deaths from pneumonia, birth asphyxia, and preterm birth complications (18). Over years, various nationwide health programs and initiatives have established by the Ministry of Health and Medical Education (MOHME) of the Iranian government to promote the health care of pregnant women, newborns, and infants, such as mother and infant care in primary health care (PHC), immunization, screening of congenital abnormalities, family physician plan, prenatal diagnosis testing and recently, health sector evolution. All of these programs aimed to reduce the maternal and children mortality rates to achieve the MDGs. Therefore, the mortality rate of children should be considered as a health issue in the region.

Another main finding of our study was a significant declining trend in mortality rates of congenital abnormalities (AARR, 6.0\%), sepsis (AARR, 8.4\%), prematurity (AARR, $24.3 \%$ ), and birth asphyxia (AARR, 14.3\%) among newborns in 2000 - 2015. We suggest that the great part of the overall reduction rate $(55.5 \%)$ was attributed to a decline in the death rates of these causes. Among the four major causes of death, congenital abnormalities with an AARR of 6.0\% remain a public health concern. A study on the trend of death causes has predicted an increasing pattern in deaths from congenital abnormalities in the long term (18). Cui et al. (5) showed a decreasing trend in the congenital 
anomalies-specific under-five mortality rate from $407.7 \mathrm{per}$ 100000 live births in 1996 to 217.4 per 100000 live births in 2013, with an AARR of $6.4 \%$ and $3.8 \%$ in urban and rural areas, respectively. They also concluded that congenital anomalies are becoming one of the leading causes of death in the community (5). A large epidemiologic study to determine global, regional, and national causes of child mortality in 2000 - 2013 showed that sepsis, prematurity, and birth asphyxia were the most common causes of neonatal deaths, followed by congenital abnormalities (2). A national study has also reported that the most common causes of mortality are congenital and chromosomal abnormalities among Iranian children aged 1-59 months (15). As a result, monitoring the trend of mortality rates and addressing the most common causes of deaths are crucial to informing what diseases to prioritize, which can help policymakers to better plan for health at national and local levels.

Despite the high coverage of immunization programs in Iran (19), there are still a number of deaths due to vaccine-preventable diseases. In our study, there was a significant declining trend in the deaths from tetanus and measles, but this descending trend was not found for pertussis mortality. There was a downward slope in the trend of measles mortality in 2003. One reason can be the mass immunization campaign against measles and rubella established in 2002 to eliminate the disease (20). In a study conducted in the Czech Republic to determine the epidemiological situation of pertussis, an upward trend in pertussis in under-one children was observed during 1997 2013 (21). Some reasons may explain this result. Rejali et al., for example, showed a high incidence rate of delayed vaccination (22); moreover, non-Iranian immigrants may also play a role in the Iranian immunization program (19).

A significant declining trend was found in the mortality of infectious diseases such as diarrhea, meningitis, and acute lower respiratory infections. Despite this declining trend, there are still some cases of mortality among children in Iran and another region (23). In addition, emerging different types of influenza and viral respiratory co-infections should be considered as an important issue in the mortality rate among children (24). A local Iranian study to evaluate the knowledge of mothers with under-five children about diarrhea reported inadequate knowledge about the diagnosis and treatment of diarrhea among this group of mothers (25), emphasizing the need for direct educational programs towards this target population. In this regard and according to the promotion of health literacy in women, an international conference on women's health is annually held in Iran (26).

We found a significant declining trend in the malaria mortality rate in under-five children during 2000 - 2015. There was no similar study for comparison, but a significant declining trend in the malaria incidence rate has been reported in recent years in Iran $(27,28)$. These findings may justify our result.

Our results also indicated that the mortality rate of HIV/AIDS had a significant upward trend as a serious public health problem, which should be considered for interventional programs (29). The proportion of HIV/AIDS deaths increased with an AARR of $0.1 \%$ over the 16 years. This is consistent with other reports in Iran and other regions, reporting an increasing trend for HIV (30). The change in the transmission patterns of HIV/AIDS in our country over time (31) may justify the upward trend in our study. For example, the role of sexual transmission has increased from $4.2 \%$ in 2001 to $21.1 \%$ in 2010 . In addition, the low proportion of HIV-testing among women (32) and the lack of awareness about HIV prevention (33) have been reported in previous studies.

\subsection{Limitations}

This study had some limitations. We used the national secondary data from the WHO reports and there was limited access to data at the provincial level. Hence, future research may make effort in local and national data collection to generate the patterns of mortality rates in children to improve the better estimation. We also did not have any information about other variables such as gender, place of residence, medication errors, or adverse drug events to perform subgroup analysis. In addition, as stated in the methods section, the age-cause-specific mortality rates were pooled to obtain the overall mortality rate in each year, which might have led to a phenomenon known as Simpson's paradox. Accordingly, the overall mortality rate in our study may differ from the rate reported by the UNICEF (17). Despite these limitations, the trend analysis of mortality rate adds insights into time changes and helps identify the potential planning issues to achieve the targets of MDGs.

\subsection{Conclusion}

The overall all-cause mortality rate in children decreased from 2000 to 2015 in Iran although this pattern varied according to the causes of death. There is still a relatively high proportion of mortality rate among children due to congenital anomalies, prematurity, birth asphyxia, sepsis, and acute lower respiratory infections. Accordingly, more effective strategies in perinatal, neonatal, and children health care are needed to achieve further prevention and control of the mortality. 


\section{Acknowledgments}

This paper used national data from the World Health Organization reports.

\section{Footnotes}

Authors' Contribution: Study concept and design: Shahab Rezaeian and Salman Khazaei; analysis and interpretation of data: Shahab Rezaeian, Salman Khazaei, and Mahmoud Hajipour; drafting of the manuscript: Shahab Rezaeian and Salman Khazaei; critical revision of the manuscript for important intellectual content: Mahmoud Hajipour, Vajihe Armanmehr, Farid Najaf, and Manoochehr Karami; all authors had an equal share in revising and approving the manuscript.

Conflicts of Interests: The authors declare that there are no conflicts of interest regarding the publication of this work.

Ethical Considerations: This study was approved by the Kermanshah University of Medical Sciences. Ethical issues (including plagiarism, informed consent, misconduct, data fabrication and/or falsification, double publication and/or submission, redundancy, etc.) have been completely observed and considered by the authors.

Funding/Support: This research has not received any specific fund.

\section{References}

1. Rajaratnam JK, Marcus JR, Flaxman AD, Wang H, Levin-Rector A, Dwyer L, et al. Neonatal, postneonatal, childhood, and under-5 mortality for 187 countries, 1970-2010: A systematic analysis of progress towards Millennium Development Goal 4. Lancet. 2010;375(9730):1988-2008. doi: 10.1016/S0140-6736(10)60703-9. [PubMed: 20546887].

2. Liu L, Oza S, Hogan D, Perin J, Rudan I, Lawn JE, et al. Global, regional, and national causes of child mortality in 2000-13, with projections to inform post-2015 priorities: An updated systematic analysis. Lancet. 2015;385(9966):430-40. doi: 10.1016/S0140-6736(14)61698-6. [PubMed: 25280870].

3. Black RE, Morris SS, Bryce J. Where and why are 10 million children dying every year? Lancet. 2003;361(9376):2226-34. doi: 10.1016/S01406736(03)13779-8. [PubMed: 12842379].

4. Reidpath DD, Allotey P. Infant mortality rate as an indicator of population health. J Epidemiol Community Health. 2003;57(5):3446. doi: 10.1136/jech.57.5.344. [PubMed: 12700217]. [PubMed Central: PMC1732453].

5. Cui H, He C, Kang L, Li Q, Miao L, Shen L, et al. Under-5-years child mortality due to congenital anomalies: A retrospective study in urban and rural China in 1996-2013. Am JPrev Med.2016;50(5):663-71. doi: 10.1016/j.amepre.2015.12.013. [PubMed: 26895742].

6. Wang H, Liddell CA, Coates MM, Mooney MD, Levitz CE, Schumacher $\mathrm{AE}$, et al. Global, regional, and national levels of neonatal, infant, and under-5 mortality during 1990-2013: A systematic analysis for the Global Burden of Disease Study 2013. Lancet. 2014;384(9947):95779. doi: 10.1016/S0140-6736(14)60497-9. [PubMed: 24797572]. [PubMed Central: PMC4165626]
7. Amiri M, Lornejad HR, Barakati SH, Motlagh ME, Kelishadi R, Poursafa P. Mortality inequality in 1-59 months children across Iranian provinces: Referring system and determinants of death based on hospital records. Int J Prev Med. 2013;4(3):265-70. doi: 10.12669/pjms.291(Suppl).3515. [PubMed: 23626882]. [PubMed Central: PMC3634164].

8. GBD 2015 Eastern Mediterranean Region Neonatal, Infant, and Under5 Mortality Collaborators. Neonatal, infant, and under-5 mortality and morbidity burden in the Eastern Mediterranean region: Findings from the Global Burden of Disease 2015 study. Int J Public Health. 2018;63(Suppl 1):63-77. doi: 10.1007/s00038-017-0998-x. [PubMed: 28776242]. [PubMed Central: PMC5702263].

9. Liu L, Johnson HL, Cousens S, Perin J, Scott S, Lawn JE, et al. Global, regional, and national causes of child mortality: An updated systematic analysis for 2010 with time trends since 2000. Lancet. 2012;379(9832):2151-61. doi: 10.1016/S0140-6736(12)60560-1. [PubMed: 22579125].

10. Motlagh M, Safari R, Karami M, Khosravi A. Life expectancy at birth in rural areas based on corrected data of the Iranian vital horoscope. Iran J Public Health. 2012;41(9):18-24. [PubMed: 23193501]. [PubMed Central: PMC3494210].

11. United Nations Development Programme. The millennium development goals report. 2015. Available from: http://www.europe.undp. org/content/undp/en/home/librarypage/mdg/the-millenniumdevelopment-goals-report-2015.html.

12. World Health Orginazation. Global Health Observatory (GHO) data: Causes of child mortality. Geneva: WHO; 2015. Available from: http: //www.who.int/gho/child_health/mortality/causes/en/.

13. Statistics and Monitoring Section DoPaP. Technical note: How to calculate average annual rate of reduction (AARR) of underweight prevalence. UNICEF. 2007. Available from: https://data.unicef.org/wp-content/ uploads/2015/12/Technical_Note_AARR_185.pdf.

14. Motlagh ME, Kelishadi R, Barakati SH, Lornejad HR, Amiri M, Poursafa P. Distribution of mortality among 1 - 59 month-old children across Iranian provinces in 2009: The national mortality surveillance system. Arch Iran Med. 2013;16(1):29-33. [PubMed: 23273233].

15. Rahbar M, Ahmadi M, Lornejad H, Habibelahi A, Sanaei-Shoar T, Mesdeaghinia A. Mortality causes in children 1-59 months in iran. Iran J Public Health. 2013;42(Supple1):93-7. [PubMed: 23865024]. [PubMed Central: PMC3712610].

16. Rezaei S, Karami Matin B, Homaie Rad E. Socioeconomic determinants of infant mortality in Iranian children: A longitudinal econometrics analysis. Int J Pediatr. 2015;3(1.1):375-80.

17. UNICEF. Levels and trends in child mortality. UNICEF; 2015. Available from: https://data.unicef.org/resources/levels-and-trends-in-childmortality-2015/.

18. Rudan I, Chan KY, Zhang JS, Theodoratou E, Feng XL, Salomon JA, et al. Causes of deaths in children younger than 5 years in China in 2008. Lancet. 2010;375(9720):1083-9. doi: 10.1016/S0140-6736(10)60060-8. [PubMed: 20346815].

19. Zahraei SM, Eshrati B, Gouya MM, Mohammadbeigi A, Kamran A. Is there still an immunity gap in high-level national immunization coverage, Iran? Arch Iran Med. 2014;17(10):698-701. [PubMed: 25305770].

20. Esteghamati A, Gouya MM, Zahraei SM, Dadras MN, Rashidi A, Mahoney F. Progress in measles and rubella elimination in Iran. Pediatr Infect Dis J. 2007;26(12):1137-41. doi: 10.1097/INF.0b013e3181462090. [PubMed: 18043452].

21. Fabianova K, Sebestova H, Benes C, Zavadilova J, Krizova P, Kriz B. [Pertussis trend in children under one year of age in the Czech Republic in 1997-2013]. Epidemiol Mikrobiol Imunol. 2014;63(4):270-276-7. Czech. [PubMed: 25523219].

22. Rejali M, Mohammadbeigi A, Mokhtari M, Zahraei SM, Eshrati B. Timing and delay in children vaccination; evaluation of expanded program of immunization in outskirt of Iranian cities. J Res Health Sci. 2015;15(1):54-8. [PubMed: 25821027]. 
23. Nascimento DSF, Oenning Martins AL, Schuelter-Trevisol F. Incidence of acute diarrhea among children aged 0 - 1 year in Southern Brazil, 2012. Arch Pediatr Infect Dis. 2015;3(4). doi:10.5812/pedinfect.28054.

24. Shatizadeh Malekshahi S, Shafiei-Jandaghi NZ, Yavarian J, Shadab A, Naseri M, Mokhtari Azad T. Detection of respiratory co-infections in children less than five years with adenovirus infection. Arch Pediatr Infect Dis. 2017;5(1). doi: 10.5812/pedinfect.36953.

25. Ghasemi AA, Talebian A, Alavi NM, Mousavi GA. Knowledge of mothers in management of diarrhea in under-five children, in Kashan, Iran. Nurs Midwifery Stud. 2013;1(3):158-62. doi: 10.5812/nms.10393.

26. Maharlouei N, Ahmadi SM, B. Lankarani K. Report on the Second Iranian International Conference on Women's Health Held May 1 and 2, 2013 in Shiraz, IR Iran. Women's Health Bullet. 2014;1(3). doi: 10.17795/whb-23654.

27. Salmanzadeh S, Foroutan-Rad M, Khademvatan S, Moogahi S, Bigdeli S. Significant decline of malaria incidence in southwest of Iran (20012014). J Trop Med. 2015;2015:523767. doi: 10.1155/2015/523767. [PubMed: 26649056]. [PubMed Central: PMC4663331].

28. Ghaffari S, Mahdavi S, Moulana Z, Mouodi S, Karimi-Nia H, Bayani $\mathrm{M}$, et al. Malaria in mazandaran, northern iran: Passive case finding during 1997-2012. Iran J Parasitol. 2012;7(3):82-8. [PubMed: 23109966].
[PubMed Central: PMC3469176].

29. Khazaei S, Rezaeian S. Increasing rate of mortality due to HIV/AIDS in Iranian children: An alarm for health policymakers. Iran $J$ Public Health. 2017;46(7):1001-2. doi: 10.17795/jjhr-33420. [PubMed: 28845417]. [PubMed Central: PMC5563864].

30. Zayeri F, Talebi Ghane E, Borumandnia N. Assessing the trend of HIV/AIDS mortality rate in Asia and North Africa: An application of latent growth models. Epidemiol Infect. 2016;144(3):548-55. doi: 10.1017/S0950268815001351. [PubMed: 26145488].

31. Haghdoost AA, Mostafavi E, Mirzazadeh A, Navadeh S, Feizzadeh A Fahimfar N, et al. Modelling of HIV/AIDS in Iran up to 2014. J AIDS and HIV Res. 2011;3(12). doi: 10.5897/jahr11.030.

32. Rezaeian S, Esmailnasab N. Social determinants of health associated with self-reported HIV testing among women. Iran J Public Health. 2013;42(4):436-42. [PubMed: 23785685]. [PubMed Central: PMC3684732].

33. Majid T, Farhad Y, Sorour A, Soheila A, Farnaz F, Hojjat Z, et al. Preventing mother-to-child transmission of HIV/AIDS: Do Iranian pregnant mothers know about it? JReprod Infertil.2010;11(1):53-7. [PubMed: 23926481]. [PubMed Central: PMC3719278]. 